LETTERS TO THE EDITOR

\section{BTS guidelines on CAP}

The new BTS guidelines on the management of community acquired pneumonia (CAP) in adults $^{1}$ are welcome if they lead to improved diagnosis of pneumonia, better assessment of severity of illness, and thus more appropriate treatment according to clinical needs. It is widely accepted, however, that inappropriate implementation of the previous guideline contributed to large increases in unnecessary use of broad spectrum antibiotics with resultant increases in antibiotic resistance and Clostridium difficile infection. The authors acknowledge this, but the new guidelines seem likely to continue this unfortunate trend.

Firstly, there is no mention of the use of oral penicillin for treatment of mild cases of CAP This is a first line choice in Scandinavian countries which have a commendably restrained history of antibiotic use (and consequently low rates of resistance). ${ }^{2}$ The new BTS guideline recommendation for widespread use of the broader spectrum amoxicillin cannot help current antibiotic resistance problems. The pharmacodynamic arguments favouring amoxicillin may be important in those areas having problems with penicillin intermediate and resistant pneumococci, but in many areas of the UK-including much of Scotland-these strains are rare. ${ }^{3}$ Did the authors consider oral penicillin as an option for mild cases?

Secondly, for treatment of severe pneumonia there is no mention of parenteral penicillin. The recommendation of co-amoxiclav or cefuroxime for this condition, while covering uncommon Gram negative pathogens and methicillin sensitive Staphylococcus aureus (MSSA), may lead to inadequate treatment of CAP due to penicillin resistant pneumococci Surely benzyl penicillin is an option in young previously healthy people with severe CAP (the majority of whom will have pneumococcal infection). ${ }^{4}$ Then, if there is a reasonable risk of infection with a pneumococcus with reduced susceptibility to penicillin, the dose of benzyl penicillin can be raised accordingly.

Thirdly, the recommendations for macrolide use in the first version of the guideline have probably been the main reason for the doubling of macrolide consumption in ou local hospital since the previous guidelines

If you have a burning desire to respond to a paper published in Thorax, why not make use of our "rapid response" option?

Log on to our website (www.thoraxjnl.com), find the paper that interests you, and send your response via email by clicking on the "eletters" option in the box at the top right hand corner.

Providing it isn't libellous or obscene, it will be posted within seven days. You can retrieve it by clicking on "read eletters" on our homepage.

The editors will decide as before whether to also publish it in a future paper issue. were introduced (unpublished observation). If this observation is indicative of a more widespread trend, it may well be contributing to the current national problem with MRSA and other macrolide resistant organisms. To what benefit I wonder? Certainly, a laboratory diagnosis of atypical pneumonia is rare in our population. Isn't this another case for stratifying patients according to risk rather than treating all severely ill hospitalised patients with a macrolide?

I appreciate the huge body of evidence considered by the authors and the disappointing number of studies which were helpful in guiding best recommendations for treatment. Nevertheless, at a time when there is widespread concern about inappropriate antibiotic use, much of it with broad spectrum agents, it is crucial that new guidelines urge restrained prescribing unless the risks (inadequate spectrum) clearly outweigh the benefits (reduced ecological damage). At the same time, severe cases require the best treatment and this should not be compromised out of a desire to do the impossible and cover all conceivable (but unlikely) pathogens all of the time.

I M Gould

Department of Medical Microbiology, Aberdeen Royal Infirmary, Foresterhill, Aberdeen AB25 2ZN UK; i.m.gould@abdn.ac.uk

References

1 BTS Standards of Care Committee. BTS guidelines for the management of community acquired pneumonia in adults. Thorax 2001:56 (Suppl IV): :ivl-64.

2 Bergan T. Antibiotic usage in Nordic countries. Int J Antimicrob Ag 2001;18:279-82.

3 Scottish Antimicrobial Resistance Surveillance (SARS). Alert organism scheme. SCIEH Weekly Report 2001;34:291-3.

4 Shann F. Bacterial pneumonia: commoner than perceived. Lancet 2001;357:2070-2.

\section{Transudates and exudates}

Joseph et al have made a valuable contribution to the evaluation of pleural effusions. ${ }^{1}$ However, we would like to sound a note of caution. Throughout all the literature, including the study by Joseph et al, one message remains the same: no single test is diagnostic for transudates or exudates. ${ }^{2}$ Thus, overreliance on such a test can be very misleading and lead to either under or over-investigation

Rarely in the literature is there any discussion regarding the place of pleural fluid protein or lactate dehydrogenase (LDH) estimation. Specifically, how does it alter management? Does the finding of a transudate obviate the need for further investigation? The main problem is that a significant number of malignant effusions are classified as transudates, whichever method is used.

The cause of a transudate is usually clinically obvious. If, however, there is no obvious underlying cause, surely cytological and/or histological examination should still be sought, as for an exudate?

Estimation of pleural fluid protein or LDH is also irrelevant if the fluid is bloodstained, as here further investigation for possible malignancy is warranted anyway.

We propose that the principal use for pleural fluid protein or $\mathrm{LDH}$ measurement is when a probable underlying cause for a transudative effusion is apparent, such as heart failure or hypoalbuminaemia, and the fluid is not bloodstained. In this situation the finding of a transudate may help to reassure that no further investigation is necessary except observation, and that a trial of treatment with, for example, diuretics may be of help.

S J Quantrill, L Dabal Department of Cystic Fibrosis, Royal Brompton Hospital, Sydney Street, London SW3 6NP, UK:

s.quantrill@ic.ac.uk

\section{References}

1 Joseph J, Badrinath P, Basran GS, et al. Is the pleural fluid transudate or exudate? $A$ revisit of the diagnostic criteria. Thorax 2001 56: 867-70.

2 Woodcock A, Viskum K. Pleural and other investigations. In: Brewis RAL, Corrin B Geddes DM, Gibson GJ, eds. Respiratory medicine. 2nd ed. London: W B Saunders, 1995: 385.

\section{Authors' reply}

We appreciate the comments by Quantrill and Dabal on our recent paper ${ }^{1}$ and would like to clarify the issues raised by them. By definition, when the pleural fluid is classified as a transudate, it indicates that a pathological process does not involve the pleural surface and that an effusion is formed because of a hydrostatic imbalance. If the pleural fluid is bloodstained, it therefore suggests disruption of the pleural membrane by an inflammatory or malignant process and hence cannot be classified as a transudate, which obviates the need for estimation of fluid LDH or protein estimation for diagnostic classification. However, as suggested by Quantrill and Dabal, an occasional malignancy may present as a transudate, in which case the mechanism is usually an effusion from collapse of a lobe causing an increase in the negative pleural pressure. Whatever the mechanism, if clinical suspicion for malignancy is high, further appropriate investigations need to be carried out.

Furthermore, Quantrill and Dabal state that hypoalbuminaemia is an apparent cause for transudative effusions. ${ }^{2}$ However, recent literature shows that hypoalbuminaemia per se may not cause pleural effusions. ${ }^{3}$ In our paper we have provided the positive likelihood ratios of the various tests so a clinician armed with the pretest probability for any individual patient and the positive likelihood ratio can work out the post-test probability using a standard nomogram..$^{45}$ In light of the above, we suggest that fluid LDH and total protein ratio are useful in the diagnostic separation of pleural effusions.

J Joseph, P Badrinath

Faculty of Medicine \& Health Science, UAE University, Al Ain, UAE

G S Basran

Respiratory Unit, Rotherham General Trust Hospital, Rotherham, UK

S A Sahn

Division of Pulmonary \& Critical Care Medicine, Medical University of South Carolina, Charleston, SC, USÁ

\section{References}

1 Joseph J, Badrinath P, Basran GS, et al. Is the pleural fluid transudate or exudate? A 
revisit of the diagnostic criteria. Thorax 2001;56:867-70.

2 Joseph J, Strange C, Sahn SA. Pleura effusions in hospitalized AIDS patients. Ann Intern Med 1993:118:656-9.

3 Eid AA, Keddissi Jl, Kinasewitz GT. Hypoalbuminemia as a cause of pleura effusions. Chest 1999;115:1066-9.

4 Sackett DL, Straus SE, Richardson WS, et al, eds. How to practice and teach EBM. 2nd ed. Philadelphia: Churchill Livingstone, 2000: 79.

5 Heffner J, Sahn SA. Mutilevel likelihood ratios for identifying exudative effusions. Chest 2002 (in press)

\section{Mycobacterium xenopi}

We read with interest the report by Bachmeyer et al on Mycobacterium xenopi pulmonary infection manifesting in an HIV infected patient after receiving highly active antiretroviral treatment (HAART). ${ }^{1}$ The diagnosis was made based on clinical, radiological, and histological findings of a granuloma in addition to one sputum specimen growing $M$ xenopi. We think that the patient may meet the criteria set by the ATS for diagnosis and treatment of disease caused by non-tuberculous mycobacteria (NTM) but, according to this guideline, these recommendations fit best for $M$ avium complex, $M$ kansasii, and $M$ abscessus. Too little is known about other NTM (such as $M$ xenopi) and how applicable these criteria are to them. ${ }^{2}$ This case may be one of those situations where it is difficult to make a definitive diagnosis.

M xenopi is usually a non-pathogenic coloniser of airways that has occasionally been associated with nosocomial outbreaks related to growth in hospital hot water systems. ${ }^{34} \mathrm{~A}$ recent publication showed the incidence of $M$ xenopi isolates in a large urban hospital and its pathogenicity to be low. ${ }^{5}$ Tuberculosis would have the same clinical/radiological presentation and would have improved with the same treatment given to the patient. ${ }^{67}$ The persistent negativity of tuberculin skin testing (TST) despite the increase in CD4 cell count canno be used to exclude tuberculosis. TST has a high false negative rate even among non-HIV infected patients with confirmed tuberculosis

While the management of this case would not have differed had the patient been treated as a presumed case of tuberculosis, it is important to keep in mind the need for contact investigation and appropriate public health interventions for tuberculosis cases.

J Salazar-Schicchi, S A Nachman Department of Medicine, Columbia University College of Physicians \& Surgeons, Division of Pulmonary and Critical Care Medicine, Harlem Hospital, 506 Lenox Avenue, New York, New York 10037, USA

\section{References}

1 Bachmeyer C, Blum L, Stelianides S, et al. Mycobacterium xenopi pulmonary infection in an HIV infected patient under highly active antiretroviral treatment. Thorax 2001;56:978-9.

2 American Thoracic Society. Diagnosis and treatment of disease caused by nontuberculous mycobacteria. Am J Respir Crit Care Med 1997; 156: s1-25.

3 Gross WM, Hawkins, Murphy DB. Origin and significance of Mycobacterium xenopi in clinical specimens. Bull Int Union Tuberc Lung Dis 1976;51:267-9.

4 Bennet SN, Peterson DE, Johnson DR, et al. Bronchoscopy-associated Mycobacterium xenopi pseudoinfections. Am J Respir Crit Care Med 1994;150:245-50.

5 Donnabella V, Salazar-Schicchi J, Bonk S, et al. Increasing incidence of Mycobacterium xenopi at Bellevue Hospital: an emerging pathogen or a product of improved laboratory methods? Chest 2000;1 18:1365-70.

6 Costrini AM, Mahler DA, Gross WM, et al. Clinical and roentgenographic features of nosocomial pulmonary disease due to Mycobacterium xenopi. Am Rev Respir Dis 1981;123:104-9

7 Subcommitte of the Joint Tuberculosis Committee of the British Thoracic Society. Management of opportunistic mycobacterial infections: Joint Tuberculosis Committee guidelines 1999. Thorax 2000;55:210-8.

\section{Authors' reply}

We thank Drs Salazar-Schicchi and Nachman for their interest in our paper and their valuable comments. However, we consider that Mycobacterium xenopi was responsible for the patient's disease despite the fact that the microbiological diagnosis was not "definitive". Indeed, the criteria of the American Thoracic Society were not fulfilled. ${ }^{1}$ These criteria do not seem to be applicable to $M$ xenopi in HIV infected patients, in whom two positive cultures of $M$ xenopi and no other cause of symptoms have been proposed as criteria for the diagnosis. ${ }^{2}$ Our patient also did not fulfil these criteria. Indeed, we were concerned about the possible role of other pathogensespecially $M$ tuberculosis_-since coexistent pulmonary infections due to other pathogens had been reported. ${ }^{3}$ However, no other pathogens were found and a search for $M$ tuberculosis in the three sputum samples and broncholoalveolar lavage fluid was negative on direct microscopic examination and culture. This is rare in cavitatory tuberculosis and makes this diagnosis unlikely.

Mycobacterium xenopi may be found in hospital water taps, hot water storage tanks, and contaminated bronchoscopes. ${ }^{4}$ Environmental contamination seemed unlikely since $M$ xenopi was not isolated from samples in the microbiology laboratory during the period of management of our patient.

We conclude that $M$ xenopi can be the cause of a lung disease in HIV infected patients that resembles tuberculosis and clinicians should not disregard the significance of this organism when isolated from respiratory specimen, even from only one.

C Bachmeyer

Département de Médecine Interne, Hôpital Laënnec, Creil Cedex, France

S Stelianides

Pneumologie, Centre Hospitalier du Vexin, Magny en Vexin, France

L Blum

Médecine Générale, Hôpital René Dubos, Pontoise, France
Correspondence to: $\operatorname{Dr} C$ Bachmeyer, Département de Médecine Interne, Hôpital Laënnec, Boulevard Laënnec, BP 72, F-60109 Creil Cedex, France; claude.bachmeyer@ch-creil.fr

\section{References}

1 American Thoracic Society. Diagnosis and treatment of disease caused by nontuberculous mycobacteria. Am J Respir Crit Care Med; 1997; 156:S1-25.

2 Juffermans NP, Verbon A, Danner SA, et al Mycobacterium xenopi in HIV-infected patients: an emerging pathogen. AIDS 1998:12:1661-6.

3 Bennett SN, Peterson DE, Johnson DR, et al. Bronchoscopy-associated Mycobacterium xenopi pseudoinfections. Am J Respir Crit Care Med 1994; 150:245-50.

4 El-Helou P, Rachlis A, Fong I, et al. Mycobacterium xenopi infection in patients with human immunodeficiency virus infection. Clin Infect Dis 1997:25:206-10.

\section{NOTICE}

\section{Pharmacology of Asthma}

A course on the "Pharmacology of Asthma" suitable for physicians or scientists with an interest in the pharmacology and therapeutics of asthma organised by Professor Peter Barnes will be held on 25-28 November 2002. For futher details contact the Postgraduate Education Centre, National Heart \& Lung Institute, Faculty of Medicine, Imperial College, Dovehouse Street, London SW3 6LY, UK. Telephone: 0207351 8172. Fax: 02073518246. E-mail: shortcourses.nhli@ic.ac.uk.

\section{CORRECTIONS}

\section{Critical care training in Spain}

In the review entitled "The pulmonary physician in critical care: towards comprehensive critical care?" by M J D Griffiths and T W Evans which appeared in the January issue of Thorax $(2002 ; 57: 77-8)$, it was incorrectly stated that: "In Spain 4 years of training are required to achieve specialist status, 2 years of which are in intensive care medicine". This should have read: "In Spain $\mathbf{5}$ years of training are required to achieve specialist staatus, $\mathbf{3}$ years of which are in intensive care medicine".

\section{Low dose of inhaled steroids and prevention of asthma death}

In the paper by $\mathrm{J} \mathrm{C}$ Kips and $\mathrm{R}$ A Pauwels entitled "Low dose inhaled corticosteroids and the prevention of death from asthma" which appeared in the 2001 Year in Review published as Supplement II in September 2001 (Thorax 2001;56(Suppl II):ii74-ii78), an error occurred in the abstract of the Introductory article by Suissa et al ( $N$ Engl $J$ Med 2000;343:332-6). In the Results section it is stated that “... the rate of death from asthma decreased by $2 \%$ with each additional canister of inhaled corticosteroids used in the previous year ...". This should have read "... the rate of death from asthma decreased by $\mathbf{2 1 \%}$ with each additional canister of inhaled corticosteroids used in the previous year ...". The publishers apologise for this error. 